\title{
The Economic Effects of Spectrum Trading*
}

\author{
Robert Leese \\ Paul Levine \\ University of Oxford \\ University of Surrey and CEPR \\ and Smith Institute
}

\author{
Neil Rickman \\ University of Surrey and CEPR
}

January 18, 2002

\begin{abstract}
We consider a model in which Cournot-Nash oligopolistic service providers are able to trade radio spectrum licences, subject to interference constraints. The terms of trade are endogenised through Nash bargaining. When the providers are in the same (geographical) market, the incentive to trade is due to cost differences; when they are in separate markets, differential demand conditions can also stimulate trade. We show that trade can enhance the productive efficiency of service provision (by concentrating production in low cost firms) but the resulting service consumer prices may have negative welfare implications. We then present numerical results from a program designed to simulate trading scenarios. these results illustrate a number of outcomes of allowing licence trades. We discuss a number of applications and extensions for our model and the relevance of our results for current government consultations on spectrum trading.

Keywords: Trading, Radio spectrum, Regulation.

JEL Classification: L10, L50, L96.
\end{abstract}

${ }^{*}$ We are grateful for financial support from the Radiocommunications Agency while undertaking this research. Errors and views expressed are our own. Please do not quote without permission. 


\section{Contents}

1 Introduction 1

2 The Channel Assignment Problem 4

3 The Core Economic Model 11

4 The One-Period Equilibria $\quad 12$

4.1 The Unconstrained Cournot-Nash Equilibrium . . . . . . . . . . . . . 12

4.2 The Constrained Cournot-Nash Equilibrium . . . . . . . . . . . . . 15

5 Channel Trade Between Two Firms 18

5.1 Intra-Market Trades . . . . . . . . . . . . . . . . . . . . . 18

5.1.1 The New Constrained Cournot-Nash Equilibrium . . . . . . . 20

5.1 .2 Bargaining . . . . . . . . . . . . . . . 22

5.2 Inter-Market Trades . . . . . . . . . . . . . . . . . . . . 23

5.2 .1 Inter-Market Re-Use . . . . . . . . . . . . . . . . . . . 24

5.2 .2 Inter-Market Exchange . . . . . . . . . . . . . . . . . . . 24

6 Trades Involving Network Operators 25

7 Simulation Results $\quad 26$

7.1 Inter-market trades . . . . . . . . . . . . . . . . . . . 27

7.2 Intra-market trades . . . . . . . . . . . . . . . . . . 28

8 Conclusions and Future Research $\quad 29$ 


\section{Introduction}

As new radio systems are brought into service and existing ones extended, the incentive to find new ways of using spectrum efficiently is increasing. One aspect of spectrum efficiency concerns the hardware used when implementing radio systems; advances in technology lead to new generations of equipment, which increase the traffic that can be carried by a given piece of spectrum. A second aspect is assignment efficiency and the channel assignment problem, namely the possible ways of assigning radio channels to individual transmitters once the hardware specification has been agreed. Both these forms of efficiency can be regarded as 'technical efficiency', namely being at the frontier of the production possibilities set and therefore producing a given amount of 'output' in some sense with the minimum amount of any given input, including the radio spectrum. This paper is concerned with a third aspect, economic Pareto-efficiency which implies but goes beyond technical efficiency.

Previous work by the authors (Leese et al. (2000)-henceforth LLR) was the first to study technical and economic efficiency in an integrated fashion. This work showed how a regulator facing a large number of licensees could make a first-best choice of a licence fees in order to maximize social welfare within the technical constraints of channel assignment. However the implementation of such a scheme makes considerable informational demands on the regulator. As well as having complete knowledge of the technical constraints, the regulator would also need to know the cost and demand conditions of all actual and potential licensees. We now propose to relax these assumptions by studying general bilateral trading mechanisms which only require the regulator to know the technical radio spectrum constraints.

Our work follows a developing theme in the general area of telecommunications policy: that "market mechanisms are superior to regulatory processes in achieving efficient transactions amongst operators. ... [assuming] ... clear rules" (Spiller and Cardilli (1997)). These authors discuss the merits of deregulation in the context of national telecommunications operators. In subsequent work, they make the 
case (based on "experiments" in New Zealand and Guatemala) for deregulation of spectrum licensing (Spiller and Cardilli (1999)).

The decentralised allocation of property rights in spectrum can take place in a variety of ways. Arguably, the auctions held in the US and the UK over the past decade provide an example of a 'market-driven' distribution of initial endowments of spectrum. Another mechanism allows trading of spectrum between users once the initial endowments are determined. Such 'spectrum trading' has been introduced abroad (Spiller and Cardilli (1999)) and promulgated in the UK, most recently in the Radiocommunication Agency's Radio Spectrum Management Review (Radiocommunications Agency (2001)). The Review argues that decentralised trade can enhance productive efficiency by placing spectrum in the hands of those who value it most highly. It acknowledges, however, that there may be objections on allocative grounds due to the anti-competitive effects of, for example, spectrum hoarding. It is interesting that the current project bears directly on this point. We show that, even in a world without asymmetric information between firms, with cooperative bargaining (and, therefore, none of the strategic reasons for capacity investment found in, say, Dixit (1980)), a danger of such hoarding still exists. In our case, this is because cost conditions in the market are such that production is most efficiently concentrated in the hands of a small oligopoly (or, indeed, monopoly).

When considering tradeable property rights (such as those created by spectrum trading), it is instructive to look at examples from other contexts, to examine the conditions most suitable for success. Tradeable pollution permits are a helpful case in point (see e.g. Tietenberg (1990)). One policy initiative which has received much publicity in this area is the US Clean Air Act 1990, whose Title IV amendments provide the first large-scale use of tradeable pollution permits. ${ }^{1}$ This legislation provided for the trading of permits for electricity generators to 'produce' SO2. Experience here suggests that the trading had several valuable effects, including reduction of SO2 emissions below target levels, encouraging the use of efficient abatement

\footnotetext{
${ }^{1}$ See Joskow et al. (1998); Joskow and Schmalensee (1998); Schmalensee et al. (1998) and Stavins (1998).
} 
technology and the creation of an efficient (and, therefore, informationally valuable) market in these permits. Interestingly, the last of these was stimulated by annual auctions of a small percentage of permits in order to publicise the common value of the permits. As a result, within four years, the number of bilateral permit trades (of the type we model here) had grown to over 5 million; 17 times the number of permits bought at auction. This suggests that, with a suitable regulatory framework (as referred to by Spiller and Cardilli (1997)), trading can flourish.

The rest of the paper is organised as follows. Section 2 provides a brief summary of the channel assignment problem and its relevance to the economic problem. Section 3 sets out the 'core' economic model of a single local market consisting of an oligopoly producing a homogeneous service requiring radio channels as an input. Section 4 then deals with two economic equilibria in a single period: first, an unconstrained Cournot-Nash equilibrium in which firms in a particular market choose levels of customer service, or 'output', and then purchase the necessary radio channels to service this output at a licence price set by the regulator. This determines total demand for radio channels given the licence price. Total supply to these markets is determined by the regulator who then sets the licence price to equate demand and supply. Firms are assumed to be large in number across all markets and therefore licence-price takers. This equilibrium is a bench-mark outcome that would require the regulator to have either complete information on firms' demand and cost conditions, or to iterate in a Walrasian fashion towards the equilibrium. The second constrained Cournot-Nash equilibrium lies at the centre of the subsequent analysis. Now we assume that the total number and distribution of radio channels is fixed and firms choose output subject to what is effectively an output capacity constraint.

Section 5 considers intra-market and inter-market bilateral trades between firms. Section 6 allows for network operators (NOs) which buy network licences as well as the local operators (LOs) considered in previous sections, and outlines a model of trade involving NOs and LOs. Section 7 the presents results from a program we have designed in order to simulate the effects of different trading scenarios. Given the 
highly complex patterns that trade might follow (and the high variety of associated outcomes), such programming is essential for understanding details of the trading process. We present result to illustrate specific several of these features, rather than presenting too wide a variety of outcomes. Section 8 concludes by discussing limitations of the analysis and directions for future research.

\section{The Channel Assignment Problem}

The channel assignment problem deals with the competing wishes to provide sufficient radio coverage while at the same time avoiding unacceptable interference between groups of transmitters (see Leese (1998)). The problem specification must therefore include information about the requirements for spectrum across the system, and also a set of constraints, designed to limit the interference levels, that a channel assignment should respect. In the version of the problem used most widely in practice, the spectrum requirements are given by specifying the number of distinct channels that each transmitter site requires. So, for instance, if there are $n$ transmitter sites, called $T_{1}, T_{2}, \ldots, T_{n}$, then we have a corresponding set of demands $m_{1}, m_{2}, \ldots, m_{n}$, where site $T_{i}$ requires the assignment of $m_{i}$ distinct channels.

The most useful specification of constraints is somewhat less clear. The commonest usual route, which reflects the use of protection ratios in the radio community, is to have a set of constraints each relating to either a single transmitter site (called co-site constraints), or a pair of transmitter sites (called inter-site constraints). To be explicit, suppose the channels are labelled by integer values, corresponding to their positions in the frequency spectrum. Then the co-site constraints require that if $f_{1}^{(i)}$ and $f_{2}^{(i)}$ are different channels both assigned to some transmitter site $T_{i}$ then

$$
\left|f_{1}^{(i)}-f_{2}^{(i)}\right| \geq \kappa_{i}
$$

for some specified minimum channel separation $\kappa_{i}$. Likewise, the inter-site constraints require that if $f^{(i)}$ and $f^{(j)}$ are channels assigned to two different transmitter 
sites $T_{i}$ and $T_{j}$, respectively, then

$$
\left|f^{(i)}-f^{(j)}\right| \geq \kappa_{i j}
$$

for some specified minimum channel separation $\kappa_{i j}$ (equal to $\kappa_{j i}$ ). The constraints are therefore completely specified by the numbers $\kappa_{i}$ and $\kappa_{i j}$, which are usually written in the form of a matrix, called the constraint matrix. The $\kappa_{i}$ make up the diagonal entries and the $\kappa_{i j}$ the off-diagonal entries.

The final part of the problem specification is the objective, for which there are two natural choices. The first and most widely studied to date is the minimum span problem, in which the aim is to find an assignment satisfying all spectrum requirements and all interference constraints, for which the span, defined as the difference between the highest and lowest channels used, is as small as possible. This would tend to be the concern of spectrum regulators and system designers. The second possibility, which we adopt in this paper and in the demonstrator, is the fixed spectrum problem, in which a maximum span is given (corresponding to the amount of spectrum available) and the aim is to assign channels to as many spectrum requirements as possible, within the given span and without violating any constraints. This would tend to be the concern of system operators, as they attempt to manage existing services. A variant on the fixed spectrum problem would assign channels to all spectrum requirements and try to minimize the number of violated constraints.

The above specification assumes that the transmitter locations and powers are fixed (they are effectively taken account of by the constraint matrix). More general formulations could have locations and powers as extra variables, to be optimized along with the channels, but there has been very little theoretical work on such problems to date.

Before moving on, it is useful to mention that the constraint matrix described above can sometimes be over-restrictive. First, it is important to realise that any mathematical model of the channel assignment problem represents an attempt to 
capture the practical requirements of radio engineers. The success or otherwise of the whole enterprise is largely determined by the accuracy of translation from the engineering specifications into mathematical specifications. As far as avoiding interference is concerned, the radio engineer generally requires that the signal-tointerference or signal-to-noise ratios should be sufficiently high at all receiver positions where radio coverage is desired. There is no mention of pairs of transmitters, but simply a requirement that the combined effects of all sources of interference are sufficiently low. If there are single dominant interferers then a constraint matrix is likely to be a reasonable mathematical model, but more generally it will be difficult to translate the engineering specification into a matrix form. Putative constraint matrices will then tend to be either too 'loose', in which case they fail to ensure the desired coverage, or too 'tight', in which case they lead to assignments using more spectrum than necessary.

The channel assignment problem has exercised many researchers over many years. The standard formulation includes, as a special case, the celebrated graphcolouring problem. A graph in this context is a collection of abstract 'nodes', some pairs of which are joined by 'edges'. The colouring problem is to attach a colour to each node in such a way that a pair of joined nodes should receive different colours and the total number of colours used should be as small as possible. The smallest number of colours needed is called the chromatic number of the graph. If we think of the nodes as transmitter sites and the colours as channels then we have precisely a minimum span channel assignment problem, in which all the $m_{i}$ are 1 , and the $\kappa_{i j}$ are 1 if the nodes $T_{i}$ and $T_{j}$ are joined and 0 otherwise. (Since only one channel is required at each site, the values given to the co-site constraints $\kappa_{i}$ are immaterial.) In physical terms, we are modelling only co-channel interference, with the edges in the graph indicating the rough location of potential coverage blackspots. Figure 1 shows a graph with chromatic number 4 , along with a possible valid colouring. (Note that our conventional definitions mean that the span is one less than the chromatic 
number. $)^{2}$

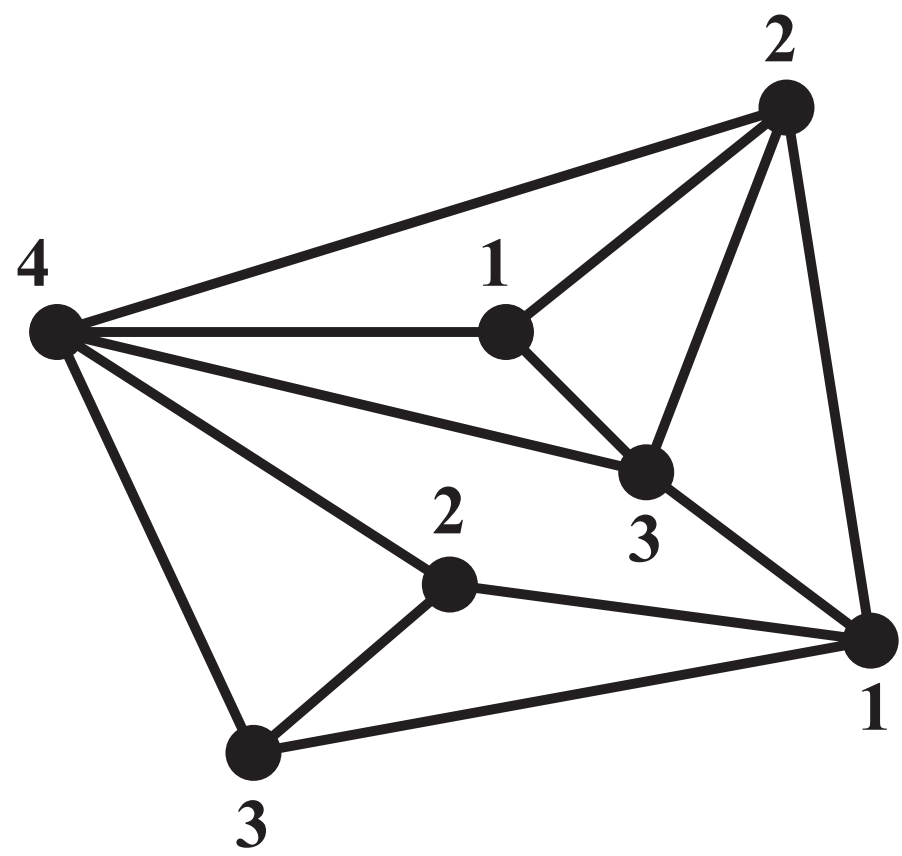

Figure 1: A Small Graph with Chromatic Number 4.

We now relate this very general formulation of the channel assignment and graph colouring problems to an economic model that explains demands for channels in terms of cost and market conditions. Each 'transmitter site' or node in the graph incorporates a local market consisting of an oligopoly of firms producing a service which we assume to be homogeneous. A spatial interpretation of nodes or sites is to regard them as equal cells (e.g. squares) comprising the region under consideration. A 'transmitter site' then consists of all the transmitters used by the firm, and it is possible that firms can share transmitters, perhaps charging an access price. We propose this as our 'core' economic model.

Each member of the oligopoly requires radio channels to provide the service. In each cell a local oligopoly provides a local service. Each firm within this market purchases a licence from the regulator to use a number of channels which depends

\footnotetext{
${ }^{2}$ Algorithms for graph-colouring have been extensively studied (see Leese (1998)).
} 
on the volume of service. The proximity of firms implies that no channel re-use is possible within a cell and we assume that there is only co-channel interference (i.e. $\kappa_{i}=1 ; \kappa_{i j}=0$ or 1$)$. The demands for radio channels in each market is the sum of individual demands of the firms in that market. We model these demands in the next section.

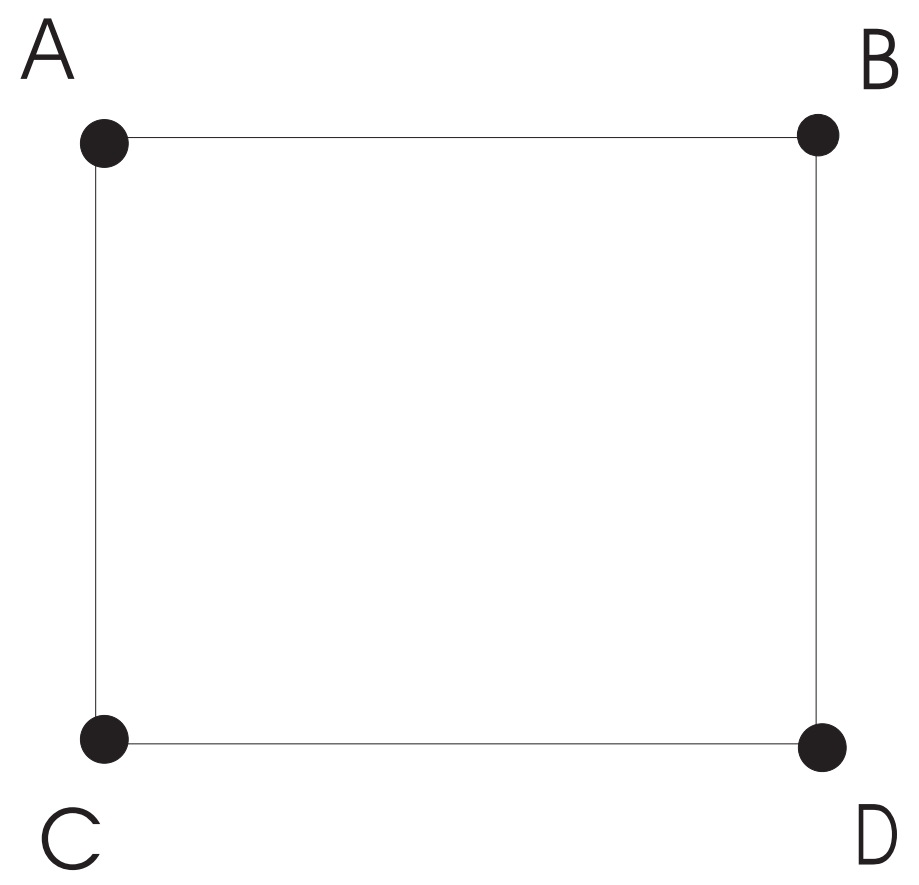

Figure 2: A 4-Node Graph of 4 Markets

There are now more channels than 'colours'. Each cell can now be given a colour and a shared colour indicates the possibility of 'channel re-use' or 'sharing' between these regions. Figures 2 to 4 illustrate this description of the channel assignment problem using a much simpler 4-node graph. The chromatic number of the graph in Figure 2 is two and Figure 3 is the corresponding constraint matrix. Figure 4 is the coloured map using two colours. Numbers inside circles are market demands and in our example demand increases as we proceed from West to East. Because diagonal squares can share channels the total demand of 60 channels can be serviced by a minimum of 40 distinct channels: say, 1-10 in market A, 11-30 in market B of which 11-20 can be re-used in market C. In market D 1-10 can be re-used from 


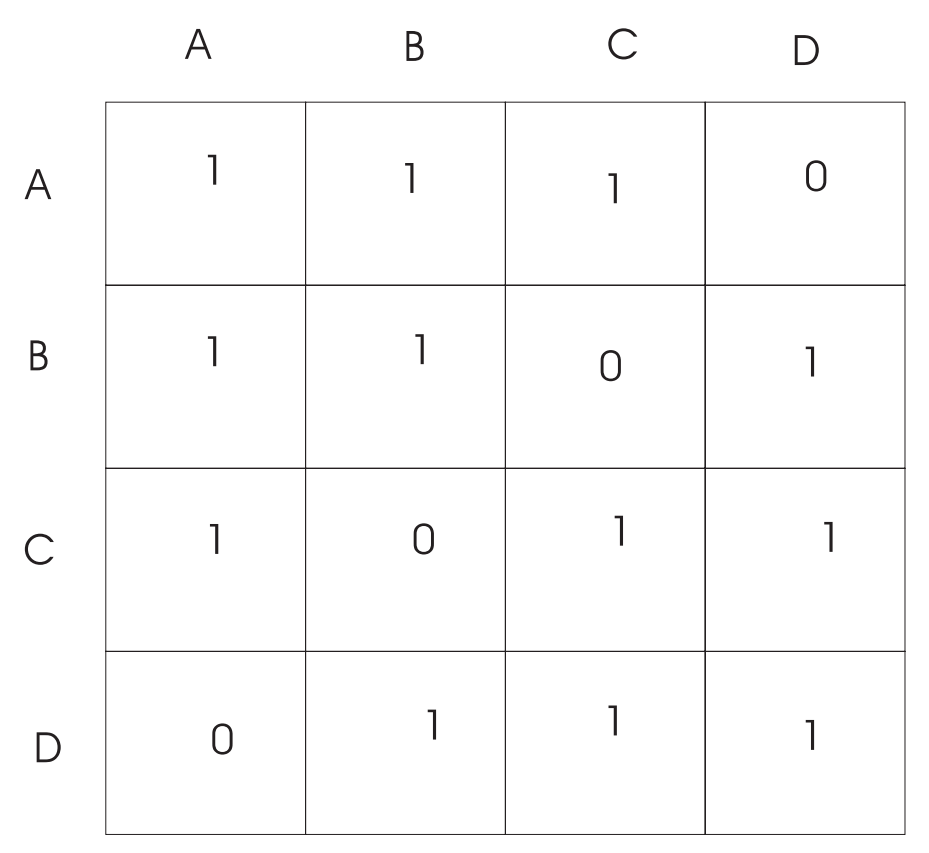

Figure 3: The Constraint Matrix

market A leaving a further distinct group of channels, say 31-40, to complete the radio channel requirements of these four markets, given the constraint matrix.

Now consider the possibility of a trade between firms situated in different oligopolies. If firms are located in the same market (i.e. square), cost conditions may be different and this provides an incentive to trade channels. If firms occupy different markets then both demand and cost conditions can be different and this provides a further incentive to trade. But some channel trades may be ruled out by the regulator for channel assignment constraint reasons. In the previous example channels 21-30 held by firms in market B can be re-used by firms in market C. Similarly channels 21-40 in market D can be re-used in market A. For firms in the same market, or in markets with different colours, only market exchange is possible. For example channels 21-30 in market B can be exchanged with (i.e. transferred to) firms in market A and channels 31-40 in market D can be exchanged with firms in market C.

It is also of interest to allow for firms to provide a service that covers more than one square. We refer to these as 'network operators' (NOs) as opposed to local 


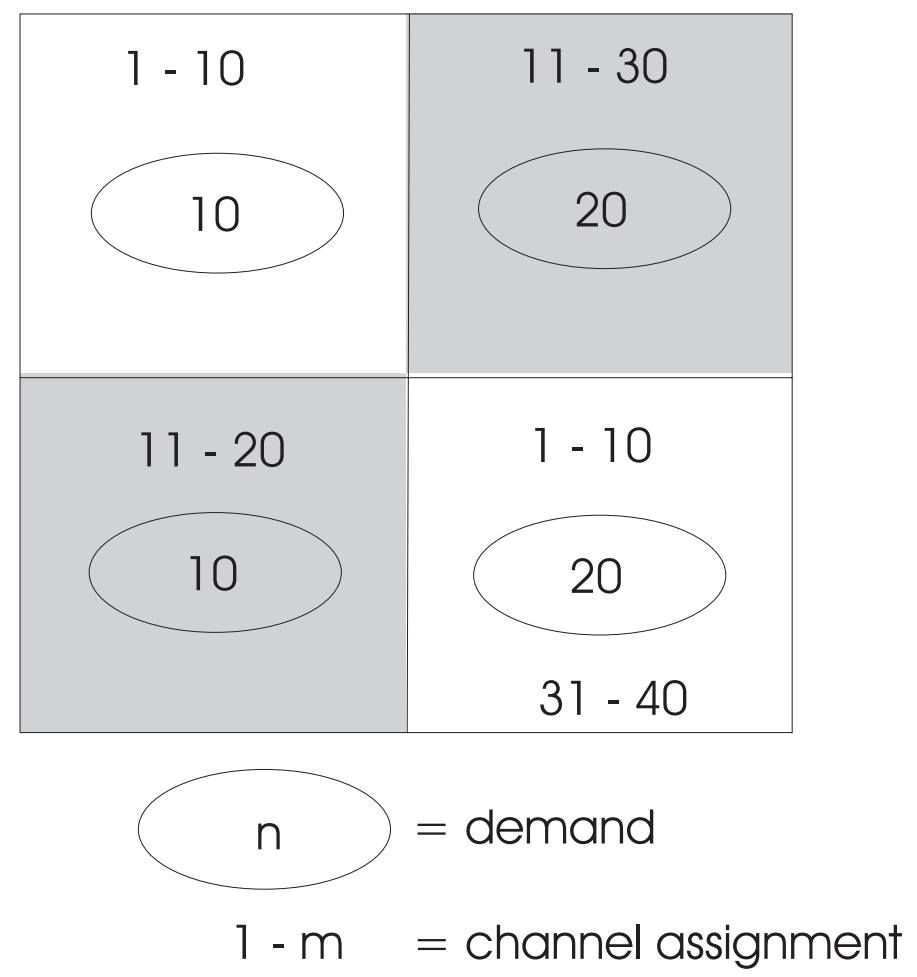

Figure 4: A Coloured Map of 4 Markets

operators (LOs). Two additional types of trade are now possible: between NOs and LOs, and those between NOs. This leads us to distinguish between the followings types of trade.

(i) Trade between LOs in the same market. No channel sharing is possible, only channel exchange.

(ii) Trade between LOs in different markets. Now both channel sharing and channel exchange is possible.

(iii) Trade between a NO and LOs in a number of markets. Only channel exchange is possible.

(iv) Trades between NOs. Both exchange and sharing is possible.

In what follows we focus on trades between LOs only and later in Section 6 we provide a sketch of trades involving NOs. 


\section{The Core Economic Model}

There are $M$ markets with $N_{j}$ firms in market $j=1,2, \ldots, M$. Market $j$ provides a homogeneous service at the market price $P_{j}$ with total market output $Q_{j}$. The demand curve is given by $Q_{j}=D\left(P_{j}\right) ; D_{j}^{\prime}\left(P_{j}\right)<0$ and we assume that $\lim _{P_{j} \rightarrow \infty} P_{j} D_{j}\left(P_{j}\right)=0$. In what follows we write the inverse demand curve as $P_{j}=D_{j}^{-1}\left(Q_{j}\right)=P_{j}\left(Q_{j}\right)$ for short. Units of output are customer-minutes provided per unit of time (say, the financial year). Without loss of generality we can choose units such that one unit of 'output' in each market requires one radio channel and output capacity equals the total number of channels available. Let $a^{R}$ be the licence price per channel per period charged by the regulator and we assume that $a^{R}$ is independent of the firm and its location.

The incentive to trade channels within a single market originates from different cost structures between firms. In an initial pre-trade equilibrium suppose that firm $i$ in market $j$ has purchased $r_{i j}$ licences at price $a^{R}$ and produces $q_{i j} \leq r_{i j}$ units of service. We choose the following quadratic functional form for the cost function:

$$
C_{i j}\left(q_{i j}, a^{R}\right)=K_{i j}+r_{i j} a^{R}+c_{i j} q_{i j}+\frac{d_{i j} q^{2}}{2}
$$

The $K_{i j}$ are fixed costs (typically capital investment) and for $d_{i j}>0$ or $<0$ we have cases of decreasing or increasing marginal costs respectively. For $d_{i j}=0$ we have constant marginal costs, as assumed in LLR. This formulation assumes that each firm is a price taker in factor markets and in the market for licences which incorporates all local markets such as the one modelled in this section. As in LLR we assume that the price elasticity of demand in the market, $\epsilon_{j}\left(Q_{j}\right)=-\frac{P_{j} d Q_{j}}{Q_{j} d P_{j}}$, is constant with respect to total output $Q_{j}$. 


\section{The One-Period Equilibria}

\subsection{The Unconstrained Cournot-Nash Equilibrium}

In the unconstrained Cournot-Nash equilibrium (UCNE), each firm chooses output and the exact number of licences required to service this output; i.e. $r_{i j}=q_{i j}$. Until we come to inter-market trade we now focus on one market, say $j=1$, and to ease the notation we drop the market subscript $j$. In a Cournot-Nash equilibrium firm $i$ then maximizes profits given by

$$
\Pi_{i}=P q_{i}-C_{i}\left(q_{i}, a^{R}\right)=\left(P-c_{i}-a^{R}\right) q_{i}-K_{i}-\frac{d_{i} q_{i}^{2}}{2}
$$

taking the output of all other firms, $\sum_{j \neq i}^{N} q_{j}=\tilde{q}_{i}$, say, as given.

Writing $P=P(Q)=P\left(q_{i}+\tilde{q}_{i}\right)$ and differentiating with respect to $q_{i}$, with $\tilde{q}_{i}$ fixed, the first-order condition for an internal maximum with $q_{i} \geq 0$ is

$$
P^{\prime} q_{i}+\left(P-c_{i}-a^{R}\right)-d_{i} q_{i}=0
$$

Then rearranging and using the assumption of a constant elasticity, firm i's market share (given the market-clearing price) is given by

$$
\frac{q_{i}}{Q}=\frac{\left(P-c_{i}-a^{R}\right) \epsilon}{P+d_{i} Q \epsilon}
$$

In a symmetric Nash equilibrium $c_{i}=c, d_{i}=d$. In LLR we assumed a symmetric equilibrium with constant marginal costs $(d=0)$. Then $(4)$ gives the mark-up pricing result:

$$
P=\frac{c+a^{R}}{1-\frac{1}{\epsilon n}}
$$

In LLR we show that $\epsilon n>\epsilon>1$ ensures that the price in a symmetric equilibrium is always positive and is also a sufficient condition for the second-order maximization condition to be satisfied. $\epsilon>1$ is also necessary for a profit-maximizing level of output to exist when the market has only one firm. In what follows we therefore 
assume a price elasticity greater than unity.

In this paper we are interested in the case where asymmetries exist between firms. Then in a non-symmetric Nash equilibrium (4) indicates the intuitive result that, given the licence price $a^{R}$ and the product market price $P$ (which in equilibrium will depend on $a^{R}$, as (5) shows), the market share of firm $i$ will increase as its productive efficiency rises (i.e. as $c_{i}$ and/or $d_{i}$ increase). As firm $i$ becomes less efficient its optimal output will approach zero and closure of the firm occurs. Before this eventuality however, because there are fixed costs independent of output, profits will be driven down to zero. We therefore introduce a participation constraint $\Pi_{i} \geq 0$ for firm $i$ in the Nash equilibrium. ${ }^{3}$ Outputs are given by solving the following system (subsequently referred to as programme $\mathbf{U C N E}$ ) of $N \leq N^{\max }$ equations in $q_{i}, i=1,2, \ldots, N$, subject to zero profit participation constraints:

$\begin{aligned} P\left(1-\frac{q_{i}}{Q \epsilon}\right)-c_{i}-a^{R}-d_{i} q_{i} & =0 \\ Q & =\sum_{i=1}^{N} q_{i} \\ P=D^{-1}(Q) & =\left[\frac{A}{Q}\right]^{\frac{1}{\epsilon}} \\ \Pi_{i} & \geq 0\end{aligned}$

We now make a convenient simplifying assumption to make the process of entry and exit tractable. We assume that

$$
K_{1}<K_{2}<\ldots<K_{N^{\max }} ; c_{1}<c_{2}<\ldots<c_{N^{\max }} ; d_{1}<d_{2}<\ldots<d_{N^{\max }}
$$

so that the efficiency of firms 1 to $N^{\max }$ can be ranked unambiguously in terms of the cost parameters. Arranging firms in order of efficiency, if the profits of the least efficient are negative, this firm is eliminated and the procedure is repeated with

\footnotetext{
${ }^{3}$ Note that in the presence of fixed $\operatorname{costs}, \Pi_{i} \geq 0$ implies that $q_{i}>0$.
} 
the remaining $N^{\max }-1$. This iterative process is repeated until we arrive at the Cournot-Nash equilibrium with all firms having non-negative profits.

The number of firms who can participate will depend on the distribution of cost parameters $K_{i}, c_{i}, d_{i}$, the parameters describing demand conditions, $A, \epsilon$ and the licence price $a^{R}$. Starting with $N^{\max }$ potential firms defined by their cost parameters, firms will leave or enter the market as demand conditions and the license price change. If the regulator releases a fixed number of radio channels for the market as whole, then the market-clearing license price will depend on this number.

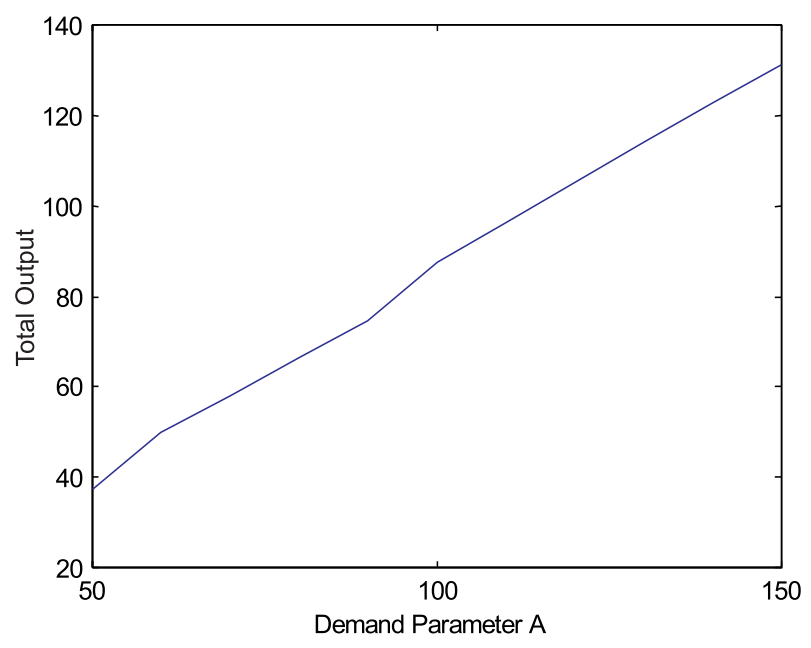

Figure 5: Output and Market Demand

Figures 5 to 7 illustrate the process of entry as market demand increases where the demand function is chosen to be $Q=A P^{-\epsilon}$ as in LLR. Parameters are chosen as follows: $N^{\max }=5, d_{i}=0, i=1,2, \ldots, N^{\max }, \epsilon=1.1, c_{1}=0.80, c_{2}=0.81$, $c_{3}=0.82, c_{4}=0.83, c_{5}=0.85, K_{i}=2.5$ and $a^{R}=0.1$. From Figure 6 for demand in the low region $A=50$, there are $N=3$ firms in equilibrium. This rises to 4 firms for $A \in[60,90]$ and $N=5=N^{\max }$ at the high level of demand $A>90$. Correspondingly, total output rises (Figure 5) and Figure 7 shows the associated profits of the 5 firms in these intervals of demand. The most efficient firm sees its profits fall at each point where $N$ increases. Once the number of firms stabilises at 


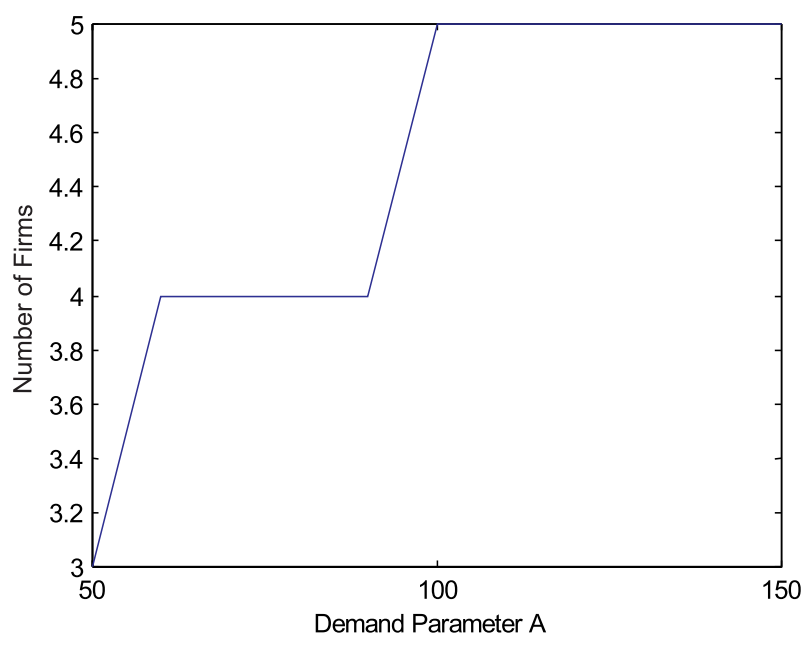

Figure 6: Participating Firms and Market Demand

$N=5$ all firms enjoy increased profit as $A$ increases.

Figures 8 to 10 examine the same process as the licence price increases from $a^{R}=0$, now keeping demand at $A=150$. Taking total output first, Figure 8 shows that a higher licence price forces up the price and lower output. Interestingly, from Figures 9 and 10, for our chosen elasticity $\epsilon=1.1$, the positive effect of a price increase on the profits of the least efficient firm outweighs the negative effect of a higher licence price, allowing it to become viable and enter the market. Profits initially fall for the most efficient four firms but then start to rise. A high licence fee therefore has the effect of redistributing surplus from consumers to producers, as well as raising revenue for the regulator, and supports a more competitive (high N) market.

\subsection{The Constrained Cournot-Nash Equilibrium}

In a constrained Cournot-Nash equilibrium, firm $i$ faces a capacity constraint $q_{i} \leq r_{i}$, where $r_{i}$ is the number of radio channels for which it has licences. It then maximizes profits given by

$$
\Pi_{i}=\left(P-c_{i}\right) q_{i}-K_{i}-\frac{d_{i} q_{i}^{2}}{2}-a^{R} r_{i}
$$




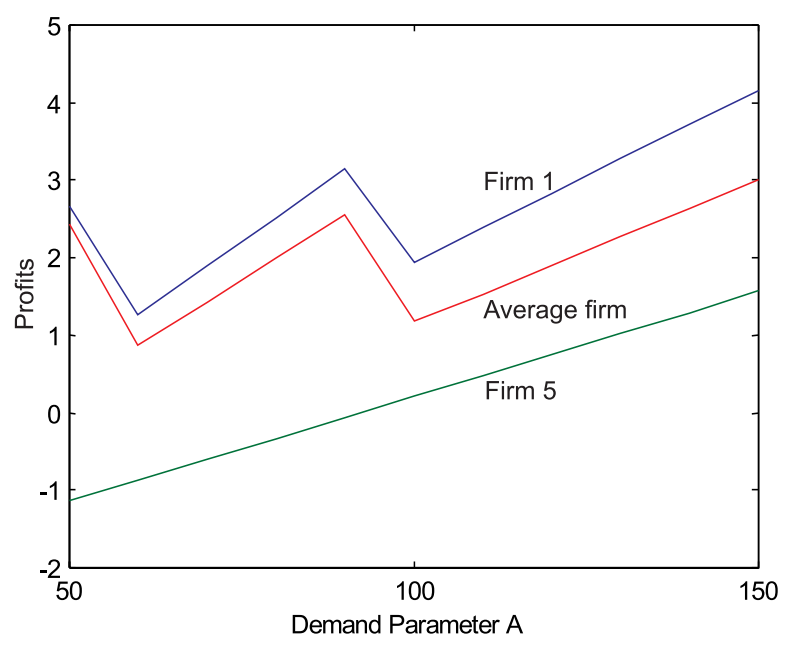

Figure 7: Profits and Market Demand

subject to this constraint, taking the output of all other firms, $\sum_{j \neq i}^{N} q_{j}=\tilde{q}_{i}$, as given, as before. Notice that licencing costs, $a^{R} r_{i}$, are now part of fixed costs and only affect the firm's participation constraint.

To carry out this constrained optimization programme, define the Lagrangian

$$
L_{i}=\Pi_{i}+\lambda_{i}\left(r_{i}-q_{i}\right)+\mu_{i} \Pi_{i}
$$

where $\lambda_{i} \geq 0$ and $\mu_{i}$ are Lagrangian multipliers associated with constraints $r_{i} \geq q_{i}$ and $\Pi_{i} \geq 0$ respectively. The Kuhn-Tucker first-order condition for a maximum is

$$
\begin{aligned}
\left(1+\mu_{i}\right)\left[P\left(1-\frac{q_{i}}{Q \epsilon}\right)-c_{i}-d_{i} q_{i}\right] & =\lambda_{i} \\
\mu_{i} \Pi_{i}=\lambda_{i}\left(r_{i}-q_{i}\right) & =0
\end{aligned}
$$

The left-hand-side of equation (9) now defines the function $\left(1+\mu_{i}\right) f\left(q_{i}\right)$. Suppose the participation constraint is satisfied; then $\mu_{i}=0$. If $f\left(r_{i}\right)>0$, then $q_{i}=r_{i}$ and firm $i$ uses all its acquired channels producing at full-capacity. If $f\left(r_{i}\right) \leq 0$, then the capacity constraint no longer holds and $q_{i}<r_{i}$ implying spare radio channels and capacity. In this case, $q_{i}$ is given by (9) with $\mu_{i}=\lambda_{i}=0$. If in equilibrium $\mu_{i}>0$, 


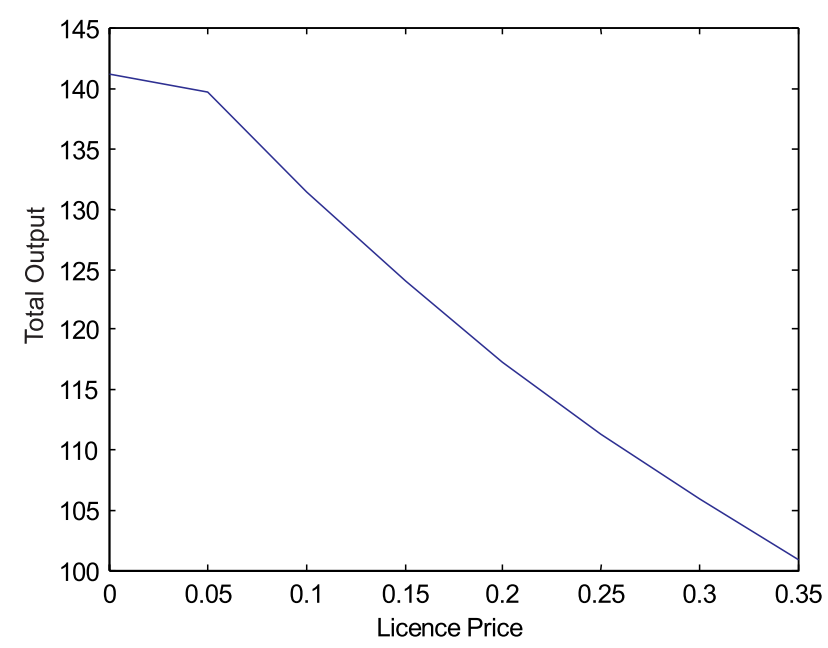

Figure 8: Output and Licence Price

$\Pi_{i} \leq 0$, the firm exits and we put $q_{i}=0$ for that firm.

The constrained Cournot-Nash equilibrium (subsequently referred to as programme $\mathbf{C C N E}$ ) is then given by solving

$$
\begin{aligned}
\left(1+\mu_{i}\right)\left[P\left(1-\frac{q_{i}}{Q \epsilon}\right)-c_{i}-d_{i} q_{i}\right] & =\lambda_{i} \\
\mu_{i} \Pi_{i}=\lambda_{i}\left(r_{i}-q_{i}\right) & =0 \\
Q & =\sum_{i=1}^{N} q_{i} \\
P & =D^{-1}(Q)=\left[\frac{A}{Q}\right]^{\frac{1}{\epsilon}}
\end{aligned}
$$

which gives $3 N$ equations in $q_{i}, \mu_{i}$ and $\lambda_{i}, i=1,2, \ldots, N$, given $r_{i}, i=1,2, \ldots, N$ and $a^{R}$. As for the unconstrained Cournot-Nash equilibrium, $N \leq N^{\max }$ is the number of firms after exits for which the participation constraint $\Pi_{i} \geq 0$. 


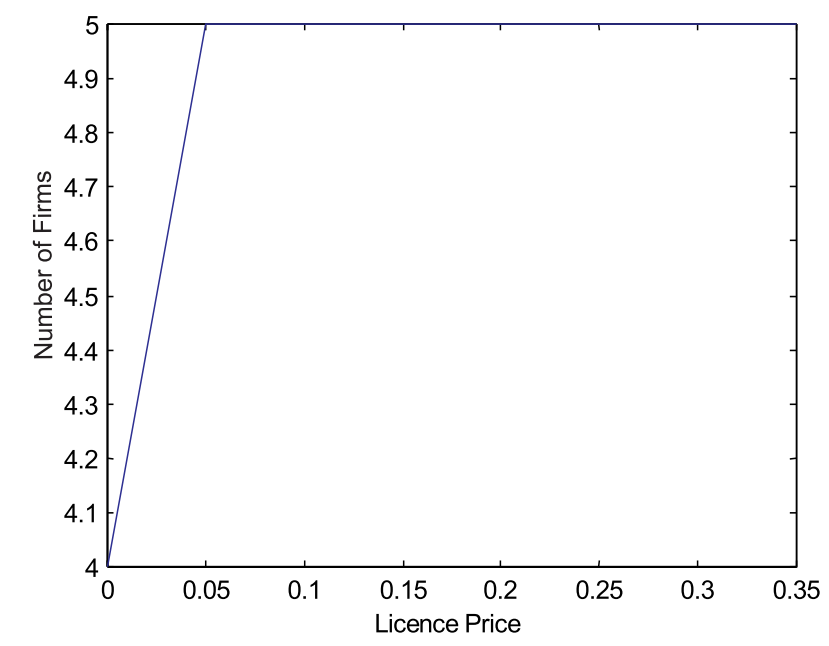

Figure 9: Participating Firms and Licence Price

\section{Channel Trade Between Two Firms}

We now allow firms to trade on a bilateral basis. After agreeing to a transfer of channels at a particular price we assume that no collusion is allowed and the two firms re-optimize with respect to output independently. Before trade commences the regulator sells radio channels at price $a^{R}$. In a UCNE, firms acquire these channels to service their anticipated output. ${ }^{4}$ No new licences are issued by the regulator during the course of the trades. Consider a series of trades at time $t=1,2, \ldots$, involving two firms at a time. Trades can be intra-market or inter-market and we consider these in turn.

\subsection{Intra-Market Trades}

Suppose at time $t$ two firms $i=f, g$ in market $j=1$ trade radio channels. As in the previous section we suppress the market subscript. When they meet at time $t$ they own $r_{f}(t-1)$ and $r_{g}(t-1)$ licences respectively, possibly affected by previous trades.

\footnotetext{
${ }^{4}$ Alternatively channels may be issued in a $a d$ hoc fashion (which we actually assume in the results from the demonstrator described in the accompanying report to the Radiocommunications Agency.)
} 


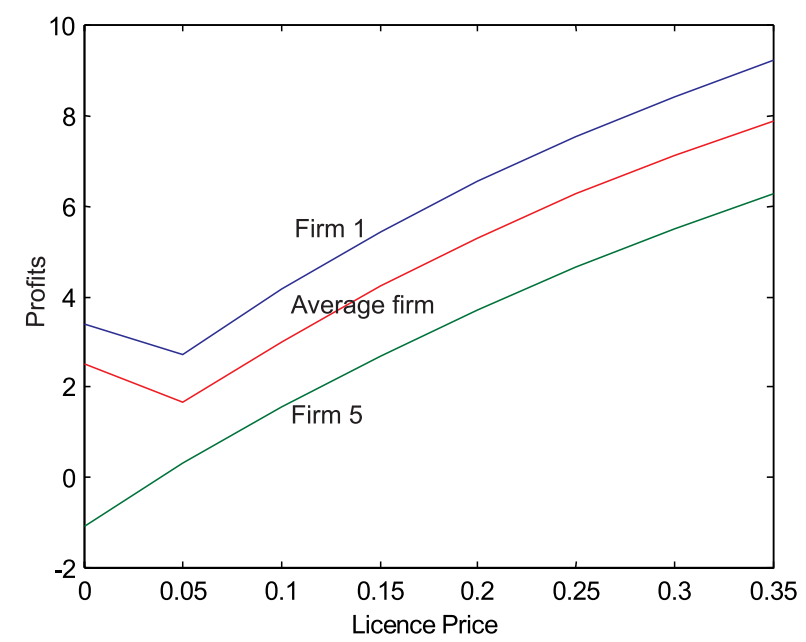

Figure 10: Profits and Licence Price

Let $e$ be the exchange (i.e. transfer) of channels from firm $f$ to firm $g$ at a price to be agreed by the two parties. We impose a constraint on the number of channels that they are permitted to exchange so that $e \leq \mu$, say, where $\mu$ is determined by the regulator. As $\mu$ is raised we then approach the case where a firm can, if it chooses, sell all its licences and cease to produce a service.

The sequencing of decisions is important in dynamic games of this type. For intra-market trades the sequence of events is:

Stage 1. Firms trade and agree a trade of $e$ channels up to a maximum of $\mu$ channels, at an exchange price.

Stage 2. Firms independently choose output levels in a new Cournot-Nash equilibrium of this stage of the game found by solving the programme CCNE where the new constraints are:

$$
r_{f}(t)=r_{f}(t-1)-e ; r_{g}(t)=r_{g}(t-1)+e
$$

The appropriate equilibrium concept is a sub-game perfect equilibrium found by backward induction at stage 2 . Notice that we assume that any future trades are 
so far into the future that these are ignored in this bargaining game. ${ }^{5}$

\subsubsection{The New Constrained Cournot-Nash Equilibrium}

Starting with the UCNE with $q_{i}=q_{i}^{N E}$ etc, it is of interest to examine stage 2 of the game. Each trade redistributes capacity which remains fixed in total. If firms continue to produce at full capacity as they do in the initial Cournot-Nash equilibrium then total output and price remain constant at their levels in the initial equilibrium. Consumers are unaffected by the trade, but firms benefit in this case. If firms produce below capacity after trade, then total output falls, the price rises and consumers lose out. The condition for price to remain unchanged in the first trade between firms $f$ and $g$ is $\lambda\left(r_{i}(1)\right)>0 \quad i=f, g$ where $r_{f}(1)=q_{f}^{N E}-e$, $r_{g}(1)=q_{g}^{N E}+e, P=P^{N E}$ and $Q=Q^{N E}$; i.e. from the first-order conditions in

\section{CCNE}

$$
\begin{aligned}
& \lambda_{f}=P^{N E}\left[1-\frac{\left(q_{f}^{N E}-e\right)}{Q^{N E} \epsilon}\right]-c_{f}-d_{f}\left(q_{f}^{N E}-e\right)>0 \\
& \lambda_{g}=P^{N E}\left[1-\frac{\left(q_{g}^{N E}+e\right)}{Q^{N E} \epsilon}\right]-c_{g}-d_{g}\left(q_{g}^{N E}+e\right)>0
\end{aligned}
$$

Using the first-order condition for the original Cournot-Nash equilibrium in UCNE where firms produce at full capacity these conditions become:

$$
\begin{aligned}
& \lambda_{f}=a^{R}+\left(d_{f}+\frac{P^{N E}}{Q^{N E} \epsilon}\right) e>0 \\
& \lambda_{g}=a^{R}-\left(d_{g}+\frac{P^{N E}}{Q^{N E} \epsilon}\right) e>0
\end{aligned}
$$

The participation constraint implies that $P_{i}^{N E}-c_{i}-a^{R}>0$. Hence from the initial Cournot-Nash equilibrium $d_{i}+\frac{P^{N E}}{Q^{N E} \epsilon}>0$ and it follows that (14) always holds. Hence from condition (15) we have the proposition:

\footnotetext{
${ }^{5}$ Alternatively, since all future trades depend on random matches and profits can rise or fall for a particular firm as a result of other firms' profits, we are assuming in effect that the expectation of future single period profits equals current profit (at stage 2).
} 


\section{Proposition 1}

Starting from a Cournot-Nash equilibrium with exogenous licence price $a^{R}$, price $P^{N E}$ and output $Q^{N E}=D\left(Q^{N E}\right)$ where $D(\cdot)$ has a constant elasticity $\epsilon$, then the first exchange of $e$ channels from firm $f$ to firm $g$ does not change the price in the post-trade equilibrium iff

$$
a^{R}>\left(d_{g}+\frac{P^{N E}}{Q^{N E} \epsilon}\right) e
$$

Now consider a sequence of $p$ trades between the most efficient firm, $g=1$ and the least efficient firms $f=N, N-1, N-2, \ldots, N-p+1$. Let $e_{i g}=\rho_{i} q_{i}^{N E}$ be the trade between firm $g$ and firm $i$ where $\rho_{i} \in[0,1]$ is the proportion of the capacity of firm $i$ transferred to firm $g$. Then generalizing the argument above, after $p$ trades the equilibrium price remains at its original Cournot-Nash level iff

$$
a^{R}>\left(d_{g}+\frac{P^{N E}}{Q^{N E} \epsilon}\right)\left(\rho_{N} q_{N}^{N E}+\rho_{N-1} q_{N-1}^{N E}+\cdots \rho_{N-p+1} q_{N-p+1}^{N E}\right)
$$

We can now show a result that confirms the fears that unregulated trading can have anti-competitive effects:

\section{Proposition 2}

If $\rho_{N}=\rho_{N-1}=\cdots \rho_{N-p+1}=1$, then for some trade $p \leq N-1$ condition (17) breaks down and channel trading then leads to a reduction in output and an increase in the price.

For example in the previous numerical example with $a^{R}=0.1$ and $A=150$ trade that transfers all radio capacity to the most efficient firm $g=1$ in turn results in a drop in output after the second trade at which point the number of firms producing is $N=3$. 


\subsubsection{Bargaining}

Now turn to stage 1 of the game where firms agree a number of channels to be exchanged, $e$, and the price. First we introduce additional notation. Consider an initial allocation of licences at time $t=0$ and subsequent trades involving pairs of firms at time $t=1,2, \cdots T$. Let $a_{i j}(t)$ be the income per period to be received, or if negative, a payment to be paid at times $t, t+1, t+2, \cdots T$ by firm $\mathrm{i}$ in market $\mathrm{j}$ as a result of a trade at time $t$. Then the total, cumulative income is given by

$$
A_{i j}(t)=a_{i j}(t)+a_{i j}(t-1)+\cdots+a_{i j}(T)
$$

As before there are $N_{j} \leq N_{j}^{\max }$ active firms in market $j$ holding licenses $\underline{r}_{j}(t)=$ $\left(r_{1 j}(t), r_{2 j}(t), \cdots r_{N_{j}, j}(t)\right)$ at time which act as capacity constraints for that period. In a constrained Cournot-Nash equilibrium the quantity vector $\underline{q}_{j}(t)$ and the price $P_{j}(t)$ are functions of the state $\underline{r}_{j}(t)$. Write total profits $\Pi_{i j}(t)=\pi_{i j}(t)+A_{i j}(t)$ as a sum of operating profits plus income from trades up to and including period $t$, where

$$
\pi_{i j}(t)=\pi_{i j}\left(\underline{r}_{j}(t)\right)=\left[\left(P_{j}\left(\underline{r}_{j}(t)\right)-c_{i j}\right] q_{i j}\left(\underline{r}_{j}(t)\right)-K_{i j}-a^{R} r_{i j}(t)\right.
$$

Consider possible trades at time t between two firms $i=f, g$ from markets $j=m, n$, say, with radio channel capacities of $r_{f m}(t-1)$ and $r_{g n}(t-1)$ respectively. A solution to the bargain with particularly attractive properties ${ }^{6}$ is found by maximizing the Generalized Nash Product.

$$
\begin{aligned}
N\left(a_{f}(t), r_{f m}(t), r_{g n}(t)\right) & =\left[\Pi_{f m}(t)-\Pi_{f m}(t-1)\right]^{\alpha_{f m}}\left[\Pi_{g n}(t)-\Pi_{g n}(t-1)\right]^{\alpha_{g n}} \\
& =\left[\Delta \pi_{f m}(t)+a_{f m}(t)\right]^{\alpha_{f m}}\left[\Delta \pi_{g n}(t)-a_{f m}(t)\right]^{\alpha_{g n}}
\end{aligned}
$$

\footnotetext{
${ }^{6}$ These are the four properties stated by Nash: (1) The final outcome should be independent of utility units. (2) The agreed outcome should be Pareto-efficient and better than no trade for both players. (3) If players sometimes agree on an outcome $\mathrm{x}$ when $\mathrm{y}$ is feasible, they will never agree on $\mathrm{y}$ when $\mathrm{x}$ is feasible (independence of irrelevant alternatives). (4) In symmetric situations, both players get the same. (See Binmore (1992), page 180)
} 
with respect to $a_{f m}(t)=-a_{g n}(t)$ and $\left[r_{f m}(t), r_{g n}(t)\right]$, where $\Delta \pi_{i j}=\pi_{i j}(t)-\pi_{i j}(t-1)$ and where $\alpha_{f m}$ and $\alpha_{g n}$ correspond to the bargaining powers of the two firms $\mathrm{f}$ in market $\mathrm{m}$ and $\mathrm{g}$ in market $\mathrm{n}$, respectively. Given $\left[r_{f m}(t), r_{g n}(t)\right]$ and for $\alpha_{f m}=\alpha_{g n}$ (equal bargaining power) it is straightforward to show that the payment made to firm $\mathrm{f}$ in market $\mathrm{m}$ is given by

$$
a_{f m}=-a_{g n}=\frac{\Delta \pi_{g n}-\Delta \pi_{f m}}{2}
$$

In other words, the payment 'splits the difference' between the gains in terms of operating profits to the two firms.

\subsection{Inter-Market Trades}

We now consider possible trades between firms in different markets. Re-introducing the subscript to denote a particular market, there are $M$ of these markets and in market $j=1,2, \ldots, M$, there are $N_{j} \leq N_{j}^{\max }$ firms in equilibrium. Costs are characterised by cost coefficients $\left\{c_{i j}, d_{i j}, K_{i j} ; i=1,2, \ldots, N_{j}^{\max } ; j=1,2, \ldots, M\right\}$ and demand by the demand function $Q_{j}=D_{j}\left(P_{j}\right)=A_{j} P_{j}^{-\epsilon_{j}}$.

Consider possible trades at time $t$ between two firms $i=f, g$ from markets $j=m, n$, say, with radio channel capacities of $r_{f m}(t-1)$ and $r_{g n}(t-1)$ respectively. Whereas before, with intra-market trade, firms could only transfer their channels, now the scope for trade is far more complicated and depends on the actual channels the firms possess and the constraint matrix discussed in Section 2. The trading process now must include a new first stage in which firms seek permission for trades from the regulator that satisfy these technical constraints. Thus we now have three stages of the game:

Stage 1. The two firms consult the regulator and discover which (if any) of their inherited radio channels $r_{f m}(t-1)$ and $r_{g n}(t-1)$ can be traded.

Stage 2. Subject to the constraints of Section 2, firms agree a number of channels to be traded, up to a maximum allowed by the regulator, and a price. 
Stage 3. Firms choose new output levels in new Cournot-Nash equilibria in both markets found by solving the programme CCNE.

We can discern two types of inter-market trades: re-use (sharing) of channels and the exchange of channels. We consider these in turn.

\subsubsection{Inter-Market Re-Use}

Suppose firm $f$ in market $m$ has channels available to share (re-use) with firm $g$ in market $n$ and agrees to share a number $s$ up to a maximum imposed by the regulator as before. After trade nothing changes in market $m$, but in market $n$ firm $g$ can increase its radio channel capacity by $s$ channels. At stage 3 of the game the CCNE is now subject to capacity constraints:

$$
r_{g n}(t)=r_{g n}(t-1)+s ; r_{f m}(t)=r_{f m}(t-1)
$$

As before at stage 2 , the quantity traded and the agreed license price $\Delta a_{f}^{T}$ agreed in the bargain is found by maximizing the generalized Nash Product.

\subsubsection{Inter-Market Exchange}

Now suppose firm $f$ in market $m$ has channels available to exchange (transfer) with firm $g$ in market $n$ they agree to exchange a number $e$ up to a maximum imposed by the regulator. After trade both markets now change and at stage 3 of the game the CCNE in the two markets is now subject to capacity constraints:

$$
r_{g n}(t)=r_{g n}(t-1)+e ; r_{f m}(t)=r_{f m}(t-1)-e
$$

Allowing for the possibility of exchange in the opposite direction $(e<0)$, there are now three possible post-trade equilibria:

(i) Some production moves from firm $f$ in market $m$ to firm $g$ in market $n$, or vice versa. 
This happens if the relative price in market $n$, in the new Nash equilibrium, is sufficiently high and/or the relative cost of firm $f$ is sufficiently high or vice versa. Some combination of these two factors are required to bring about trade in these directions.

(ii) Production shifts to the efficient firm who may also move to the high demand region.

For example production moves from firm $f$ in market $m$ to firm firm $g$ in market $n$ who then geographically replaces $f$.

(iii) One firm takes over the other.

By this we mean that a firm in one market can service the demand in the second market with a new cost structure that may capture, for example, increasing returns to scale. In general we are not assuming that all markets produce the same service (although we do assume a homogeneous good within a market). A takeover therefore only applies to two firms who are producing the same service but selling in different markets.

\section{Trades Involving Network Operators}

Suppose now there are $N^{N O}$ firms operating in all $M$ regions and that firms acquire network licences which can be used anywhere on the network. Firm $i$ produces $q_{i}^{N O}$ units of output across the network of which $w_{i j} q_{j}^{N O}$ are serviced in region $j$ where $\sum_{j=1}^{N} w_{i j}=1$. Figure 11 shows an example of 4 cells as before with the same constraint matrix. Total output is 100 and numbering cells A, B, C and D as 1, $2,3,4$ respectively, we have $w_{i 1}=0.2, w_{i 2}=0.3, w_{i 3}=0.1$ and $w_{i 4}=0.4$. If the costs of servicing a customer are invariant with respect to their location then the cost structure is exactly as before except for the cost of the channel licences. For the constraints implied by Figure 11 the minimum number of distinct channels necessary to service $q_{i}^{N O}$ units of output are given by

$$
r_{i}^{\min }=\left[\max \left\{w_{1}, w_{4}\right\}+\max \left\{w_{2}, w_{4}\right\}\right] q_{i}^{N O}
$$




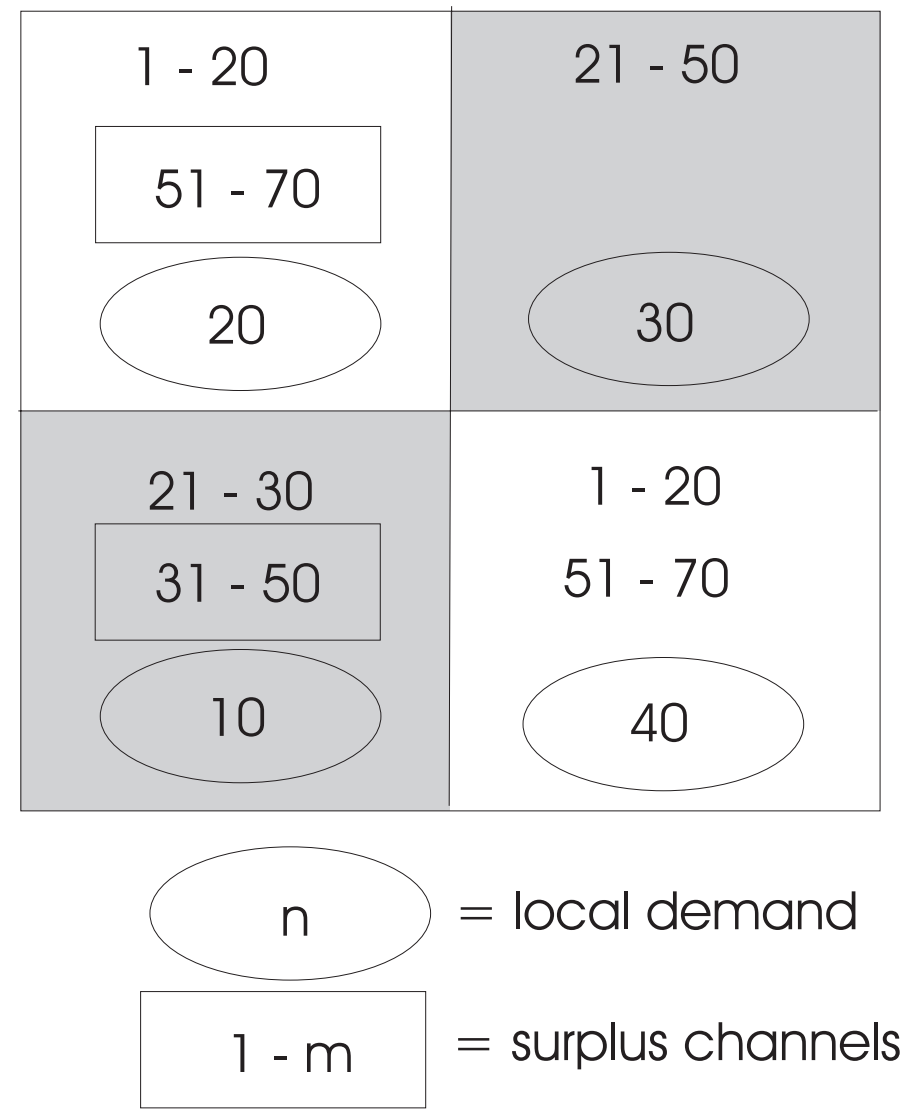

Figure 11: Demand and Surplus Channels with a Network Operator

which equals 70 for this example. Figure 11 shows a possible channel assignment of channels $1-70$. The UCNE follow as before except that the price per channel is now $r^{\min } a^{R}<a^{R}$ because of the scope for sharing channels in cells of the same colour. The channels shown in rectangles in cells A and C are now surplus and could be sold on to LOs in these cells or to other NOs which have higher concentrations of customers in one or both of these cells.

\section{Simulation Results}

In order to examine the effects of licence trading within the above framework, we have designed a software program (in MathCad 2001). This searches sequentially for 
trades and allows them if gains exist and interference constraints are not violated. For programming convenience, we assume that firms onty trade one licence at a time. We choose initial values as follows: $A_{j}=5, \epsilon_{j}=1.2, c \in\{0.5,1.0,1.5\}, n_{j} \in$ $\{1,2,3,6\}$. We assume six licences per market, which that may be the result of piecemeal policy over the years. ${ }^{7}$ We then proceed to look at trades within a single market ('inter-market trades') and trades between markets 'intra-market trades'). Below we present some illustrative findings.

\subsection{Inter-market trades}

To begin, consider a market with two firms, with marginal costs of $\mathbf{c}=(1.0,1.5)$, each holding three licences. The initial equilibrium has a market price of 2.14 , profits of $\Pi=(1.46,0.46)$ and consumer surplus of 21.47. Outputs are $\mathbf{x}=(1.28,0.72)$. In this case, there is no incentive to trade: neither firm gains sufficiently from the price effects restricting its rival's output (by buying a licence) and then increasing its own.

A slight change generates trade, however. Suppose that $\mathbf{c}=(0.5,1.0)$, each firm with three licences. Initial market price is 1.29 , we have $\Pi=(2.13,0.28)$ and consumer surplus of 23.77. Outputs are $\mathbf{x}=(2.71,0.99)$ - both high as a result of the firms' lower marginal costs in this example. There is now an incentive to trade from firm 1 to 2 (the high cost firm). (Trade the other way would not alter constraints sufficiently to change outputs.) This restricts firm 1's output and allows the high cost firm gain sufficiently from the resulting high price to make trade worthwhile. This indicates the role of licences as credible commitments to constrain output. In fact, trade will continue here until firm 2 has all six licences and a high cost monopoly results. final price is 6, firm 2's profit has doubled to 0.53, but consumer surplus has fallen to 17.47: total welfare (the sum of consumer surplus and profits) falls from 26.18 to $20.38 .^{8}$

\footnotetext{
${ }^{7}$ Justification for these initial configurations can be found in Hurley et al. (2001).

${ }^{8}$ This result differs from our earlier theory, where licences gravitate towards the efficient firm
} 
As we allow $\epsilon$ to rise, this result eventually disappears. The reason is straightforward: the more elastic is demand, the smaller is the price effect of restricting output, so the lower is the high cost firm's gain rom doing so. Indeed, as $\epsilon$ rises past 1.4, the incentives to trade reverse and a single trade from firm 2 to firm 1 takes place.

Suppose we now have more firms (say, $n=6$ ), with marginal costs of $\mathbf{c}=$ $(0.5,0.5,0.5,1.0,1.0,1.5)$, and each firm having one licence. A variety of possibilities now emerge, depending on the sequence of trades. However, the outcomes can be partitioned into two sets. In the first of these, one of the low cost firms monopolises the market (trade ends when it holds all six licences). The productive efficiency of this outcome is not always enough, however, to increase total welfare, because of the resulting increase in price. In the second set of outcomes, each of the three lowest cost firms finishes with two licences (the others have none). In this case, the benefits of low cost production are enough to offset the (weaker) effects of concentration on price, with the result that this set typically increases total welfare. ${ }^{9}$

\subsection{Intra-market trades}

Now suppose that there are four markets, with associated interference constraints as pictured in Figure 2. A key issue now emerges because it is possible for trading not to terminate. The reason is that the transfer of a licence across markets has effects on prices in both. Thus, firms that may not have been thinking of trading may suddenly become keen to do so. One solution to this is to introduce a threshold

\footnotetext{
because of our programming assumption that the initial allocation of licences is arbitrary. This may reflect the 'real world' situation, but also means that there may be inefficiency in the initial position from which trade takes place. The result does, however, indicate the role played by licences in this set-up. Effectively, they provide credible output commitments in the sense that, if firm 1 buys a licence from firm 2 (whose output constraint was binding), this must force firm 2's output down. Thus, unlike other Cournot settings, firm 1 will enter the trade certain that the resulting market price will not be competed down by deviation from its rival.

${ }^{9} 100$ replications of the program produced the second outcome 25 times, a statistically significantly smaller number of times than the first outcome. To the extent that the regulator would prefer the second outcome, it would be interesting to examine institutional arrangements that encourage trading patterns which generate this.
} 
gain from trade below which trades do not take place. ${ }^{10}$ In this case, convergence of the trading process becomes more common (in the sense that trading becomes increasingly infrequent as searches for trades take place).

To give an example, assume there are two firms in each market in Figure 2 (i.e. 8 firms in total) and recall that, given the figure, channels cannot be re-used at adjacent nodes, but can be at diagonally opposite ones. One firm in each market has marginal co st of 0.5 , the other has marginal cost of 1.0 . There are 9 channels: Market A has channels 1 and 2; B has channel 3; C has channels 1, 2 and 9; and D has channels $3,4,5,6,7$ and 8 . This allocation satisfies the interference matrix constraints in Figure 2.) The details of how these are split amongst the firms can be found in Hurley et al. (2001). Now suppose a trading threshold of 1; i.e. only trades yielding gains of at least this much can take place. In this case, one trade takes place (from the high cost firm in D to that in B). This raises output and lowers price in B sufficiently to increase total welfare (aggregated across the four markets). A lower trading threshold (0.75) encourages a second trade and welfare decreases in our examples. Moving to a threshold of 0.5 encourages enough trade that local monopolies can emerge. In particular, we find that the low cost firm in each case acquires three licences each but that total welfare drops. Once the threshold is at 0.2 , trade ceases to terminate - an interesting result given that the number of markets, and firms in each, is relatively small.

\section{Conclusions and Future Research}

We have presented a model to investigate the potential economic effects of spectrum trading amongst firms who require spectrum licences as part of their activities. Trading takes place within the technical interference constraints enforced by a regulator. The model can, in principle, accommodate a variety of markets and firms, as well as both channel exchange and channel re-use (i.e. sharing across different markets).

\footnotetext{
${ }^{10}$ One possible interpretation of this would be a lump-sum tax imposed on the 'capital gains' resulting from a trade.
} 
Our most detailed analytical results have focused on trade amongst oligopolists in a given (geographical) market. In this context, our results suggest that trade can enhance productive efficiency by placing licences in the hands of firms who value them most (i.e. low-cost firms). However, there is a danger that this process may cause higher consumer prices which, in turn, could offset the welfare effects of lower cost production. Subsequent discussion suggests that similar forces are likely to prevail in the other market settings we cover. An important outcome of our modelling is to make clear a role played by licences: they provide credible commitment mechanisms to restrict output. Unlike in other Cournot settings, the sale of a licence forces a firm's output down (assuming it was fully utilising its licences): the licences act as capacity constraints.

We have also presented numerical results to illustrate the outcomes trade might create. In the context of inter-market trades, we showed that trade need not occur and that, if initial allocations are not optimal, they may induce high-cost monopolies. Other examples illustrated the trade-off from out theoretical model: productive efficiency versus price rises through increased concentration: we found cases where trade increased and decreased welfare. We have also seen that the outcomes of trading my be pathological, with some outcomes being more desirable than others. This suggests that the design of trading institutions matters. Turning to intramarket trades, we have seen that trade generally will not terminate, because of external price effects as licences are transferred across markets. The imposition of suitable trading thresholds can overcome this problem. Further simulation work is required to gain a full understanding of the complex forces underlying these results, but our illustrative results suggest that trade may have a variety of outcomes.

There are a number of directions in which our work could be extended in order to provide a more complete picture of the effects of spectrum trading. To begin with, our model assumes complete information between potential traders. This may, perhaps, be feasible amongst local taxi firms (at least as a first approximation), where market conditions and competitors may be well known. It is less likely, 
however, to prevail for inter-market trades or for trades between network operators, where the potential for commercially sensitive information and strategic behaviour may be significant. In such circumstances, the costs of reaching agreement can be significant, as experience negotiating network access terms in New Zealand has demonstrated (see Spiller and Cardilli (1997)).

This suggests that the efficiency of the trading process we have modelled may be compromised be two types of transactions cost associated with information asymmetries: bargaining costs and search costs. In the first case, our use of the Nash bargaining solution may need modification to allow for other potential disagreements between negotiators. Such 'non-cooperative bargaining' involves considerable technical complexity (see e.g. Osborne and Rubinstein (1990); Kennan and Wilson (1993)) and may, for practical purposes, constrain the situations that can be modelled. One possible means of overcoming the potential hold-out problems that can arise here is provided by the US Clean Air mini-auctions: the evidence suggests that these helped identify an appropriate range of prices for pollution permits and, therefore, kick-started the pattern of bilateral trades.

Turning to search costs, our model assumes that parties can identify potential traders costlessly. While, again, this may not be unreasonable in a small local market, it will be harder to achieve in a densely populated local market or in many inter-market trades. Theoretical work on 'matching' in markets provides some useful algorithms for resolving these problems (see Osborne and Rubinstein (1990), ch. 9) and it would be sensible to investigate how easily these could be incorporated into the current demonstrator.

Another aspect of trading that we have not considered is the temporal aspect where firms trade and bargain taking into account the implications of each trade for future production and trades. Simultaneous trades also raise complications. We have circumvented these problems by assuming that trades are sequential and the time between each trade is sufficiently great to warrant a myopic calculation of the consequences of the next trade. These assumptions are clearly restrictive. By 
relaxing our assumption that firms are myopic, spectrum would become an asset, and we would need to consider the potential for intermediate 'spectrum agents' and expectations-based trading.

In terms of extensions, it would also be possible to consider other forms of market competition (such as Bertrand price competition) and product differentiation within a geographical market. Both of these would fit the current framework, and would allow the model to cover a particularly wide variety of market situations.

Finally, it is important to make clear how our current work (and potential extensions) can link into the current policy consultations in the UK. The Radiocommunications Agency (2001) consultative document (pp. 33-38) raises several questions in relation to spectrum trading. To illustrate how our work may be adapted to consider such questions, we suggest three links here. To begin, there are questions of whether trading may damage allocative efficiency by encouraging anti-competitive practices (para. 106); this is a danger illustrated by the current demonstrator. Next, the document asks how such trade might affect investment by existing and potential operators (para. 111); this is a question that could be examined by adding an initial investment period to our existing set-up.

As our third illustration, Question xxxvii asks what "market infrastructure" may be needed to facilitate trade. This echoes mini-auctions used under the US Clean Air Act and suggests that we should consider the role for market intermediaries to lubricate trade. Our work also suggests another intriguing institutional factor that may lubricate trade: the initial allocation of spectrum amongst firms. Simple reflection on graphs like that in Figure 2 indicate that there may be circumstances where interference constraints reject otherwise productively efficient trades. A solution to this would be for the regulator to make available extra measures of spectrum (perhaps more than that required to meet current demands). This could allow firms to 'trade round' interference problems and place licences with low-cost firms.

It is clear that much interesting work remains to be done before the net effects of spectrum trading can be fully understood. Hopefully, however, the present paper 
demonstrates the potential benefits of integrating economic and channel assignment tools for analysing the issues involved. The model is flexible enough to be extended in a variety of ways and may, therefore, provide a useful framework for future research in this important policy area.

\section{References}

Binmore, K. (1992). Fun and Games: A Text on Game Theory. Heath, Lexington, Mass.

Dixit, A. (1980). The role of investment in entry-deterrence. Economic Journal, 90(357), 95-106.

Hurley, S., Leese, R., Levine, P., Rickman, N., and Whitaker, R. (2001). An investigationinto thje effects of spectrum trading. Report to the Radiocommunications Agency, London.

Joskow, P. L. and Schmalensee, R. (1998). The political economy of market-based environmental policy: The U.S. acid rain program. Journal of Law and Economics, 41(1), 37-83.

Joskow, P. L., Schmalensee, R., and Bailey, E. M. (1998). The market for sulfur dioxide emissions. American Economic Review, 88(4), 669-685.

Kennan, J. and Wilson, R. B. (1993). Bargaining with private information. Journal of Economic Literature, 31(1), 45-104.

Leese, R. (1998). Mathematical methods in radio frequency aassignment. In Proceedings of the 14 th International Wroclaw Symposium on Electromagnetic Compatibility, Poland, pages 644-647.

Leese, R., Levine, P., and Rickman, N. (2000). Exploration into the relationship between mathematical and economic problems of spectrum allocation. Report to the Radiocommunications Agency, London. 
Osborne, M. and Rubinstein, A. (1990). Bargaining and Markets. Academic Press, Boston, Mass.

Radiocommunications Agency (2001). Radio Spectrum Management Review: A Consultation Paper. London.

Schmalensee, R., Joskow, P. L., Ellerman, D., Montero, J. P., and Bailey, E. M. (1998). An interim evaluation of sulfur dioxide emissions trading. Journal of Economic Perspectives, 12(3), 53-68.

Spiller, P. T. and Cardilli, C. (1997). The frontier of telecommunications deregulation: Small countries leading the pack. Journal of Economic Perspectives, 11(4), $127-138$

Spiller, P. T. and Cardilli, C. (1999). Towards a property rights approach to communications spectrum. Yale Journal on Regulation, 16, 53-83.

Stavins, R. N. (1998). What can we learn from the grand policy experiment? Lessons from SO2 allowance trading. Journal of Economic Perspectives, 12(3), 69-88.

Tietenberg, T. H. (1990). Economic instruments for environmental regulation. $O x$ ford Review of Economic Policy, 6(1), 17-34. 